\title{
Depressive Symptoms among Kuwaiti Population Attending Primary Healthcare Setting: Prevalence and Influence of Sociodemographic Factors
}

\author{
B. Al-Otaibi ${ }^{a} \quad$ A. Al-Weqayyan ${ }^{b} \quad$ H. Taher ${ }^{b} \quad$ E. Sarkhou ${ }^{\text {b }} \quad$ A. Gloom ${ }^{c} \quad$ F. Aseeri ${ }^{d}$ \\ E. Al-Mousa ${ }^{\text {e H. Al-Zoubi }}{ }^{\text {e S. Habeeba }}{ }^{b}$ \\ ${ }^{a}$ Ahmadi Health District, ${ }^{b}$ Mishref Family Practice Health Center, ${ }^{C}$ Kuwait Psychiatric Hospital, \\ ${ }^{d}$ Capital Health District, ${ }^{e}$ Farwania Health District, Kuwait
}

\section{Key Words}

Beck Depression Inventory • Depression, prevalence •

Primary healthcare $\cdot$ Kuwait

\begin{abstract}
Objectives: The aim of this study was to estimate the prevalence of depressive disorders and the influence of sociodemographic characteristics on primary healthcare (PHC) setting in Kuwait. Subjects and Methods: A cross-sectional survey was conducted in $\mathrm{PHC}$ setting in Kuwait using the Beck Depression Inventory second edition questionnaire (BDI II) as a screening instrument, together with a sociodemographic questionnaire. A representative sample drawn from the target population consisted of 2,320 subjects of $\mathrm{Ku}$ waiti nationality randomly selected from $18 \mathrm{PHC}$ centers covering all Kuwait governorates during the period from April 2003 to January 2004. The target age group was 21-64 years. Participants were asked to complete the BDI II questionnaire consisting of 21 items reflecting the depressive disorder independently. Sociodemographic data such as sex, age, marital status, children, occupation, educational status, chronic diseases and social problems were included in the questionnaire. The optimum cutoff score for BDI II was estimated. Results: A total of 2,320 participants completed the questionnaire, 1,082 (46.8\%) male and 1,237 (53.2\%) female; $860(37.1 \%)$ screened positive for depressive symptoms,
\end{abstract}

among whom 352 (15.3\%) were male and 508 (21.7\%) female. Of all participants, 163 (7.0\%) were severely depressed, 314 (13.5\%) moderately depressed and 383 (16.5\%) mildly depressed. Depressive disorder was more prevalent among women than men, young than old, more among highly educated individuals, working participants, married individuals, and parents with 3 or more children. Conclusion: Depressive disorder is a highly prevalent condition among Kuwaiti patients attending PHC setting. Chronic diseases and social problems are risk factors for depressive disorder.

Copyright $\odot 2007$ S. Karger AG, Base

\section{Introduction}

Depression is among the most common debilitating psychiatric conditions, with 1 in 8 individuals requiring treatment during their lifetime [1]. On average $12 \%$ of patients seen in primary healthcare (PHC) settings have depressive disorders [2]. All ages are prone to depression, which manifests as a combination of feelings of sadness, loss of interest, loneliness, worthlessness, hopelessness, irritability, agitation and guilt accompanied by physical symptoms. The impact of depression on the community is greater than that of many chronic physical diseases. The economic and social costs of depressive disorders are high; it is estimated to be similar to that of cancer and

\section{KARGER}

Fax +4161306 1234

E-Mail karger@karger.ch

www.karger.com (c) 2007 S. Karger AG, Basel

1011-7571/07/0165-0384\$23.50/0

Accessible online at:

www.karger.com/mpp
Eman Sarkhou

Primary Health Care, Ministry of Health, PO Box 4561

22046 Salmiya (Kuwait)

Tel. +965 538 5397, +965 533 6810, Fax +965 5385397

E-Mail drsorkhou@hotmail.com 
ischemic heart disease [3]. The risks associated with depressive disorders include impaired function, reduced production, loss of human life by suicide, increased treatment costs, frequent attendance at PHC center and increased sick leave. While guidelines encourage PHC physicians to diagnose and treat their depressed patients, rates of detection and treatment in PHC are still suboptimal [1]. A review of published studies suggests that $\mathrm{PHC}$ physicians fail to detect depression, which remains undiagnosed in one third to one half of the cases [4-7]. Recognizing depression in PHC settings may be particularly challenging because time is limited in busy PHC settings and patients, especially men, rarely spontaneously describe emotional difficulties. On the contrary, somatic presentation such as fatigue, sleep problems, pain or multiple persistent vague symptoms may hinder recognition and management of depression in PHC setting. Several reasons are given to explain evidence that recognizing and diagnosing depression may be impeded by some factors including perceived stigma of mental health treatment, patient's somatization and denial, lack of ample physician knowledge and skill, time constraints, concerns about confidentiality and fear of the treatment. The PHC physician's ability to detect depressive disorder is of fundamental importance in preventing suicide and reducing healthcare costs as patients are more frequent users of medical services.

Proper diagnosis of depression in $\mathrm{PHC}$ requires routine screening. Fortunately, many formal screening tools are available, and since there is no clear evidence that one screening tool is better than another, the choice of a screening tool is determined by clinician personal performance, patient population served and the practice setting [8]. Many studies [8-12] have concluded that the Beck Depression Inventory second edition (BDI II) yields reliable and valid scores in a PHC setting, suggesting that the use of BDI II in this setting may improve detection and treatment of depression. The BDI II is a well-documented standardized instrument [8-12]. It is a self-report measure of depression intended to assess the existence and severity of symptoms of depression as listed in the American Psychiatric Association's diagnostic and statistical manual of mental disorders [8]. The symptoms range from 1 (= sadness) to 21 (= a lack of interest in sex).

This study attempts to determine both the prevalence and severity of depression among Kuwaiti citizens attending PHC centers using BDI II and the impact of the sociodemographic factors on the prevalence of depression.

\section{Methods}

The study was approved by the Ministry of Health. A crosssectional sample survey was conducted during the period April 2003 to January 2004. PHC was used as the sampling frame, and a random table was used to select 18 PHC centers from all governorates in Kuwait. The selected sample represents $25.7 \%$ of all PHC clinics in Kuwait.

Questionnaires were distributed to 2,372 Kuwaiti clients attending PHC clinics; age of participants ranged from 21 to 64 years. Clients who had not been on medication for any psychotic disease within the last month were screened upon presenting to the clinic for any reason. The study was explained to everyone attending the clinic; those who refused participation were excluded. Verbal consent was obtained from each participant who completed the questionnaire independently. Incomplete questionnaires were excluded from the study.

An Arabic version of the revised edition of BDI II in its complete form obtained from Kuwait Psychiatric Hospital was used; the questionnaire was translated by a group of psychiatric specialists before we intended to do this study. A pilot study was conducted on 50 individuals in one health centre to ensure the reliability of the questionnaire. The association between sociodemographic characteristics (such as age, gender, education, marital status, number of children if any, chronic diseases and social problems) and the BDI II score was determined. Each question had four responses and subjects were instructed to circle the answer that best described their response, the choices having values varying from 0 to 3; individual response item values were compiled for a total BDI score as previously described [10,13]. The BDI total score was interpreted as follows: completely normal: $0-14$; mild depression: 15-20; moderate depression: 21-29; severe depression $\geq 30$. The survey was anonymous to insure confidentiality. Incomplete questionnaires were excluded from analysis.

$\chi^{2}$ test was used to compare the two variables. Mann-Whitney test was used to compare the two age groups. Data were collected and processed by SPSS, Version 11.0.

\section{Results}

Of the 2,372 questionnaires distributed, 2,320 were completed, for which there were $1,082(46.8 \%)$ male respondents and 1,237 (53.2\%) female. Of the 2,320 participants, 860 (37.1\%) screened positive for depressive symptoms and among them 352 (15.3\%) and 508 (21.7\%) were male and female, respectively. The prevalence of depression for males and females according to the severity of depression is given in table 1. Overall more females 509 (21.9\%) than males 351 (15.1\%) were depressed. Proportionately $154 / 1,082(14.2 \%)$ and $125 / 1,082(11.5 \%)$ of males were mildly and moderately depressed as opposed to 229/1,237 (18.5\%) and 89/1,237 (15.2\%) of females. However, proportionately, the percentage (prevalence) of severe depression was approximately equal in both males 72/1,082 (6.6\%) and females 991/1,237 (7.3\%). 
Table 1. Severity of depression in males and females according to BDI II score

\begin{tabular}{lllll}
\hline Gender & $\begin{array}{l}\text { Total } \\
\mathrm{n}(\%)\end{array}$ & $\begin{array}{l}\text { Mild } \\
\mathrm{n}(\%)\end{array}$ & $\begin{array}{l}\text { Moderate } \\
\mathrm{n}(\%)\end{array}$ & $\begin{array}{l}\text { Severe } \\
\mathrm{n}(\%)\end{array}$ \\
\hline Male & $1,082(46.8)$ & $154(6.6)$ & $125(5.4)$ & $72(3.1)$ \\
Female & $1,237(53.2)$ & $229(9.9)$ & $189(8.1)$ & $91(3.9)$ \\
Total & $2,320(100)$ & $383(16.5)$ & $314(13.5)$ & $163(7.0)$ \\
Z ratio & & 0.000 & 0.015 & 0.313 \\
\hline
\end{tabular}

$\mathrm{Z}$ normal test for the difference between two properties. The cutoff point for testing the ratio is $47 \%$ for males based on their representation in the sample.

The influence of sociodemographic characteristics on the prevalence of depressive disorders is shown in table 2 . All demographic variables used in this study showed statistical significance with $\mathrm{p}$ values below 0.05 levels, indicating that observed differences are not due to statistical error. When analyzed within each age group, younger subjects, 649/1,807 (35\%), showed less depression than older participants, 211/515 (41\%). Work was another factor determining depressive symptoms. Nearly $26.9 \%$ of working subjects were depressed compared to $5.3 \%$ for unemployed and $5.0 \%$ for retired subjects.

\section{Discussion}

Unfortunately, depression often goes unrecognized in PHC setting [1]. A number of earlier studies have shown that PHC physicians often overlook depressive disorders and lack the needed skills for recognizing, responding, diagnosing and treating depressive disorders $[14,15]$. This is understandable since $\mathrm{PHC}$ physicians are confronting an array of complex problems, and depressed patients often see their physicians for a reason other than depression, exacerbating the difficulty in diagnosing depression in the PHC setting. The overall prevalence of depressive disorders was 37.1\%, similar to a study in Saudi Arabia [16], and confirms the high prevalence of depressive disorders in PHC setting $[1,14]$. The high depression scores on BDI II may be related to the patient's extreme distress or the high prevalence of personality disorders in this group of patients. It could reflect the inability of $\mathrm{PHC}$ physicians to diagnose depressive disorders.

In the present study, a variety of social and medical factors have been considered in an attempt to explain the higher rate of depressive disorders in Kuwaitis.
Table 2. The influence of sociodemographic factors on depression

\begin{tabular}{|c|c|c|c|c|}
\hline Variable levels & $\begin{array}{l}\text { Not depressed } \\
\text { n (\%) }\end{array}$ & $\begin{array}{l}\text { Depressed } \\
\mathrm{n}(\%)\end{array}$ & $\chi^{2}$ test & $\mathrm{p}$ value \\
\hline \multicolumn{5}{|l|}{ Age, years } \\
\hline $21-44$ & $1,158(49.9)$ & $649(28.0)$ & 4.658 & $<0.05$ \\
\hline$\geq 45$ & $302(13.0)$ & $211(9.1)$ & & \\
\hline \multicolumn{5}{|l|}{ Sex } \\
\hline Male & $730(31.5)$ & $352(15.3)$ & 16.09 & 0.0001 \\
\hline Female & $730(31.5)$ & $508(21.7)$ & & \\
\hline \multicolumn{5}{|l|}{ Work } \\
\hline Yes & $1,018(43.9)$ & $623(26.9)$ & 10.30 & $<0.05$ \\
\hline No & $274(11.8)$ & $122(5.3)$ & & \\
\hline Retired & $168(7.2)$ & $115(5.0)$ & & \\
\hline \multicolumn{5}{|l|}{ Education } \\
\hline$<$ High school & $254(10.9)$ & $193(8.3)$ & 36.33 & 0.0001 \\
\hline High school & $447(20.6)$ & $283(12.2)$ & & \\
\hline$\geq$ University & $729(31.4)$ & $384(16.6)$ & & \\
\hline \multicolumn{5}{|l|}{ Marital status } \\
\hline Single & $305(13.1)$ & $233(10.0)$ & 58.81 & 0.0001 \\
\hline Married & $1,055(45.5)$ & $523(22.5)$ & & \\
\hline Divorced & $100(4.3)$ & $104(4.5)$ & & \\
\hline \multicolumn{5}{|l|}{ Children } \\
\hline$\geq 3$ children & $703(30.3)$ & $435(18.8)$ & 34.63 & 0.0001 \\
\hline$<3$ children & $339(14.6)$ & $96(4.1)$ & & \\
\hline Childless & $418(18.0)$ & $329(14.2)$ & & \\
\hline \multicolumn{5}{|l|}{ Chronic diseases } \\
\hline No & $747(32.2)$ & $336(14.5)$ & 31.81 & 0.0001 \\
\hline Yes & $713(30.7)$ & $524(22.6)$ & & \\
\hline \multicolumn{5}{|l|}{ Social problems } \\
\hline Yes & $452(19.5)$ & $486(20.9)$ & 146.73 & 0.0001 \\
\hline No & $1,008(43.3)$ & $374(16.1)$ & & \\
\hline
\end{tabular}

Age, education, work status, and marital status are plausible explanations for gender difference, which could be due to hormonal changes during postpartum, premenopausal and menopausal periods, putting them at risk for depression. Furthermore, women make significantly more visits than men to the healthcare centers and are usually better than men in expressing their feelings. The findings of the present study are similar to previous ones $[14,17-19]$. As for age, our finding differs from the previously reported one where the older age group was more prone to have depressive disorders than the younger one [17].

The association between level of education and prevalence of depression shows that the prevalence of depression increases with increasing level of education. This does not conform to other studies, in which patients with lower educational levels were more likely to have clinically significant depressive symptoms $[17,18]$. There is no 
definite explanation for this result, but we suggest that highly educated people may be frustrated about their expectations and perceptions about society which at times may not be achievable.

An unexpected result was the high prevalence of depression among the working population, especially mild and moderate types, which was lower for non-working and lowest among the retired. Our result is different from previous results of other studies where work was suggested as a source of expression, happiness, self-confidence and financial support for people, and that retired people are more prone to develop depressive disorders [10, 13]. A possible explanation may be due to a lack of job satisfaction or the possibility that work could be a source of anxiety, which leads to depression among Kuwaitis.

The high prevalence of depressive disorders among married men and women was obvious especially in women. One explanation may be due to marital disharmony, increased marital responsibilities and their consequences, which may lead to an increased rate of depression among Kuwaitis. With regard to the association between marital status and prevalence of depression, the majority of depressed participants were among the married group and the least were among the divorced group. This result was unexpected and not similar to previous studies [17, 18], but could be explained by marital responsibilities and the resulting discord or friction between married $\mathrm{Ku}$ waitis.

The study also revealed that depressive symptoms were greater among parents with 3 or more children than those parents without children. It was obvious that women and men with 3 or more children are more prone to develop depression. This result was similar to results of other studies [5].

The results of the present study show that a relationship between chronic illnesses and current depression exists with chronic diseases increasing the rate of depression, especially mild and moderate depression. This finding was confirmed by other studies $[8,16,19]$.

Concerning the influence of social problems on the rate of depression, our findings suggest that patients' negative life events and social problems, chronic diseases, or dysfunctional marital relationship may indicate a high risk for depression. This finding was supported with results from other studies [13].

With regard to assessing the severity of depression, it was found that mild and moderate depressive disorders were more prevalent than severe depression in men and women. This result was similar to other studies, where the majority experienced mild depression [20].
There are several limitations that one must consider when interpreting the results of this study. The results cannot be used as final estimation of the rates of detection and treatment of depression in primary healthcare because our study population was defined by those who scored positive on a screening instrument rather than those who are truly depressed by standard diagnostic criteria since any screening instrument is not $100 \%$ sensitive and specific. Some patients with 'false-positive' results on this screening may have dysthymia (chronic low-grade depression) or minor depression due to anxiety, panic, post-traumatic stress or grief reaction during the period of screening conduction and still others may have no disorders at all. Despite these limitations, we believe that the results of this study have potential to help improve the quality of care for depression. The positive results of this study were encouraging, given the importance of diagnosing depression in the PHC setting. In fact, recent guidelines by the US Preventive Service Task Force recommend screening for depression in PHC [21].

\section{Conclusion}

Depressive disorder is a highly prevalent condition among Kuwaiti patients attending primary healthcare setting. Chronic diseases and social problems are risk factors for depressive disorder. Based on these results, we recommend primary health care physicians should be adequately trained to recognize and initiate management of this disorder.

\section{Acknowledgment}

We would like to thank Ali Ahmad Abdelkareem, a student in Universal American School, for his great help and contribution in this study.

References

1 Gill MJ, Dansky BS: Use of electronic medical records to facilitate screening for depression in primary care. Primary Care Companion. J Clin Psychiatry 2003;5:125-129.

-2 Spitzer RL, Kroenke K, Linzer M, Hahn SR, Williams JB, deGruy FV: Health related quality of life in primary care patients with mental disorders. JAMA 1995;274:15111517.

- Wing YK: Recent advances in the management of depression and psychopharmacology. Hong Kong Med J 2000;6:85-92. 
4 Dowrick C, Buchan I: Twelve months outcome of depression in general practice. BMJ 1995;311:1274-1280.

$\checkmark 5$ Leung KK, Lue BH, Lee MB, Tang LY: Screening of depression in patients with chronic medical diseases in a primary care setting. Family Practice 1998;15:67-75.

6 Gater R, Tansella, Korten A, Tiemens GB, Mavreas VG, Olatawura MO: Sex differences in prevalence of depressive and anxiety disorders in general health care settings. Arch Gen Psychiatry 1998;55:405-413.

7 Otero AA: Subdiagnostico de la depression por el medico generalista. Psicopatologia 1999; 19:63-66

$>8$ Sharp LK, Lipsky MS: Screening for depression across the life span. Am Fam Physician 2002;66:1001-1008.

$>9$ Viinamaki H, Tanskanen A, Honkalampi K, Koivumaa-Honkanen $\mathrm{H}$, Haatainen $\mathrm{K}$, Kaustio O, Hintikka J: Is the Beck Depression Inventory suitable for screening major depression in different phases of the disease? Nord J Psychiatry 2004;58:49-53.
10 Arnau RC, Meagher MW, Norris MP, Bramson R: Psychometric evaluation of the Beck Depression Inventory-II with primary care medical patients. Health Psychol 2001; 20:112-119.

11 Richter P, Werner J, Heerlein A, Kraus A, Sauer H: On the validity of the Beck Depression Inventory. Psychopathology 1998;31: 160-168.

12 Storch EA, Roberti JW, Roth DA: Factor structure, concurrent validity and internal consistency of the Beck Depression Inventory-Second Edition in a sample of college students. Depress Anxiety 2004;19:187-189.

13 Beck AT, Steer RA, Ball R, Ranieri W: Comparison of Beck Depression Inventories I and II in psychiatric outpatients. J Pers Assess 1996;67:588-597.

14 Gabarron HE, Vidal RJM, Haro AJM, Boix SI, Jover BA, Arenas PM: Prevalence and detection of depressive disorders in primary care. Aten Primaria 2002;29:329-336.

15 Becker SM: Detection of somatization and depression in primary care in Saudi Arabia. Soc Psychiatry Psychiatr Epidemiol 2004;39: 962-996
6 Al-Shammari SA, Al-Subaie A: Prevalence and correlates of depression among Saudi elderly. Int J Geriatr Psychiatry 1999;14:739747.

17 Zung WW, Broadhead WE, Roth ME: Prevalence of depressive symptoms in primary care. J Fam Pract 1993;37:337-344.

18 Bertakis KD, Helms LJ, Callahan EJ, Azari R, Leigh P, Robbins JA: Patient gender differences in the diagnosis of depression in primary care. J Women Health Gend Based Med 2001;10:689-690.

19 Callahan EJ, Bertakis KD, Azari R, Helms LJ, Robbins JA, Miller J: Depression in primary care: patient factors that influence recognition. Fam Med 1997;29:182-183.

20 Berardi D, Leggieri G, Berti Ceroni G, Rucci P, Pezoli A, Paltrinieri E, Grazian N, Ferrari G: Depression in primary care: a nationwide epidemiological survey. Fam Pract 2002;19: 397-400.

21 Berg AO, US Preventive Services Task Force: Screening for depression: recommendations and rationale. Am Fam Physician 2002;66: 647. 